Biotechnology and animal welfare

Temple Grandin, Ph.D.

Assistant Professor, Department of Animal Sciences, Colorado State University, Fort Collins, Colorado 80523 USA

Biotechnology is a huge field. This discussion will be limited to processes which require the manipulation of genetic material to produce a substance which is administered to a farm animal or manipulation of the animal's own genetic material. This paper is not intended to be a comprehensive review of all animal related biotechnology research but rather a brief outline of both the detrimental and positive effects of biotechnology on animal welfare. In the last section of the paper ethical questions will be discussed from the viewpoint of the author who has had years of experience in making practical improvements in animal handling and slaughter

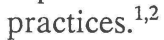

The use of biotechnology with farm animals can be divided into seven basic categories. The first category is the use of substances produced by biotechnology methods to improve the productivity of farm animals. One example is growth hormone injections. The second category is transgenic animals where a gene from another species is incorporated into an animal. An example is the insertion of human growth hormone genes into pigs. The third category is transgenic animals used as animal models in biomedical research and the fourth category is creating mosaic animals which are combinations of two species which normally do not interbreed. The fifth use of biotechnology is inserting genes into animals which will enable them to make medically valuable substances in their milk. The sixth area is deleting or adding genes to study basic principles of gene expression or replacing faulty genes to correct a genetic defect. The last category is an indirect use of biotechnology. Examples would be diagnostic tests and DNA fingerprinting.

\title{
GROWTH HORMONE AND VACCINES
}

Early experiments with porcine growth hormone indicated that high doses had very detrimental effects on the welfare of pigs. Very high doses of $10.34 \mathrm{mg}$ to $54.7 \mathrm{mg}$ per day resulted in liver and kidney degeneration, edema and arthritis. ${ }^{1}$ A lower dose of $6.11 \mathrm{mg}$ per day had no ill effects. L. J. Machlin concluded that pigs were much more sensitive to the detrimental effects of high doses of growth hormone compared to rats. ${ }^{3}$

A review of all the abstracts in the growth and development section of the 1990 book of abstracts published by the American Society of Animal Science indicated that doses under $6.11 \mathrm{mg}$ per day were used in most of the studies reported at this year's meeting of the society. ${ }^{4}$ The use of porcine growth hormone (PST) in moderate doses 
will probably not cause the problems cited by Machlin. In one recent study of Duroc and Pietrain pigs, PST and control slaughter weight pigs had no differences in behavior, general health, leg problems or carcass abnormalities. ${ }^{5}$

In the United States, pigs are often transported long distances from the farm to the slaughter plant. After arrival at the slaughter plant the pigs are housed in unheated stockyard pens. Stan Curtis, at Pennsylvania State University, calculated that excessive leanness may result in cold stress problems during transport. The midwestern U.S. becomes very cold during the winter. Temperatures often get down below -17 degrees C.

There are also concerns about pushing animals beyond their physiological limits. Some pigs already have leg soundness problems. In the U.S. poultry industry, 2 to $6 \%$ of all broiler chickens have skeletal problems. ${ }^{6}$ Elbert Day, professor at Mississippi State University, states that sudden death syndrome and skeletal deformities are highly associated with rapid growth. ${ }^{3}$ In both the pork and poultry industries, there are skeletal problems occurring without the addition of growth hormone. Some researchers have concluded that skeletal deformities and leg weakness "is the price that must be paid for rapid growth of broilers. ${ }^{5}$

There is some evidence that porcine growth hormone will increase bone thickness in pigs. Metacarpal thickness and diameter was greater in pigs treated with $3 \mathrm{mg}$ of PST per day. ${ }^{7}$ This may provide stronger bones in mature animals kept for breeding but may result in more elastic bones during the growth stages. ${ }^{7}$ There is a possibility this could cause welfare problems for a rapidly growing fattening pig which is marketed prior to maturity. In elderly humans growth hormone injections increase lean body mass, decrease fat, increase bone density and skin thickness. ${ }^{8}$ To put it simply, they may reverse some of the detrimental effects of aging. Growth hormone is a substance that can have both detrimental and beneficial effects. It depends on how we use it.

Bovine growth hormone (BST) will increase milk production in dairy cows. A major welfare concern is that already high producing dairy cows will have further stressors placed on their physiology. Dairy cows treated with growth hormone require a high level of nutrition to prevent a decline in body condition. A University of Maine study indicated that dairy cows treated with growth hormone and fed an all forage silage diet with no grain had a slight decrease in body condition at the end of a 98-day trial. ${ }^{9}$ Injections were started late in lactation on the 186th day. If this trial had been started earlier in lactation it is likely that body condition would have further declined. Grain supplements may be required to maintain the body condition of dairy cows on BST.

On a few poorly managed U.S. dairy farms, cows are allowed to decline to a very skinny condition. Observations by the author at slaughter plants indicate that about $2 \%$ of the dairy cows arrive at the plant in a horrible skinny weak condition. The use of growth hormone will require better nutrition and a higher level of management expertise to prevent an increase of this type of problem.

Another area of welfare concern is frequent injections. In many studies, pigs received a daily injection of growth hormone. ${ }^{4}$ Other studies have shown that a reduced injection schedule of two injections per week is also effective. ${ }^{5}$ Rough handling or dull needles may cause distress to pigs during frequent injections.

To reduce the need for frequent injections, implants which release the hormone slowly are being developed for dairy cows. In some studies these implants are being 
placed under the skin near the tail head. I am concerned about pain to the cow to install the implant every two weeks. It has to be inserted with a thick needle. I am also concerned about the implant migrating and getting into hamburger after slaughter. It is my opinion that all implants should be placed in the ear.

Another problem which will have to be addressed if BST and PST become widely used is injection site abscesses. In the beef industry, injection site abscesses from vaccinations are a serious problem. Rod Bowling of Monfort of Colorado estimates that injection site abscesses cost the U.S. beef industry $\$ 1.44$ per head. ${ }^{10}$

Injection site abscesses are also a serious problem in pigs. Pigs will often get systemic abscesses which form large pockets of pus far away from the injection site. Injections with dirty needles or of substances which are irritating will greatly increase abscesses. ${ }^{11}$ The solution to the problem would be the development of ear implants which would last many weeks.

Biotechnology could really improve animal welfare through the development of better animal vaccines. Researchers at Texas A\&M have genetically altered the Brucellosis bacteria so that it no longer causes the disease, but will still provide immunity. As research continues, better vaccines against additional animal diseases could be developed. Michael Fox, Humane Society of the U.S., warns that products of this type may make it possible to stock animals at even greater densities in confinement systems. ${ }^{12}$ This would be very detrimental to animal welfare.

Increased disease resistance in domestic animals could also be detrimental to wildlife..$^{13}$ If a vaccine could be developed for African Sleeping Sickness, cattle could be moved into new areas and directly compete with wildlife. The welfare of the cattle may be improved, but the welfare of wildlife may be damaged. These two points are legitimate concerns, but they are not justification for discontinuing research on better vaccines.

\section{TRANSGENIC FARM ANIMALS}

In 1982, R. D. Palmiter and his colleagues inserted rat growth genes into mice and created giant mice. ${ }^{14}$ In 1983 they achieved the feat of creating giant mice by inserting human growth genes. ${ }^{14}$ The giant mice were normally proportioned and they were able to pass the human growth gene on to their offspring. ${ }^{15}$ The human growth gene was heritable in the standard Mendellian manner. In 1985, R. E. Hammer in collaboration with R.D. Palmiter accomplished the more difficult task of producing transgenic rabbits and pigs which expressed human growth hormone. ${ }^{16}$ Reseachers at the University of Edinburgh have now succeeded in producing transgenic lambs which can also pass human genes on to their offspring. ${ }^{17}$

Transgenic pigs and mice with human growth genes exhibited pathological abnormalities and a shorter life span. ${ }^{18}$ However, the infirmities were much more serious in the pigs. Transgenic pigs which expressed human growth hormone were lame, lethargic and uncoordinated. They also had ulcers, degenerative joint disease, pericarditis, endocarditis, nephritis and pneumonia. ${ }^{18}$

The health problems in the transgenic swine were an exaggeration of health problems which occur in the regular commercial pig population. V. G. Pursell and his 
colleagues believe that the infirmities observed in pigs, which express human growth hormone, "would have been less frequent and less severe if the genetic base used in our experiments had been selected for structural soundness of legs and the ability to withstand commercial rearing conditions." ${ }^{18}$ In transgenic pigs, human growth hormone is expressed in many different tissues. Pursell suggests that many of the infirmities are caused by a long-term exposure to growth hormone. ${ }^{18}$ They may just be overdosed all over the body. There are still many things that need to be learned about gene expression. In the mouse experiments, researchers found that there was a poor correlation between gene dosage and the degree of gene expression in the tissues.

Mice respond to a greater extent to human growth hormone genes compared to pigs. Possibly centuries of selection for growth may limit the pigs ' response to growth hormone. ${ }^{18}$ Researchers in Edinburgh, England found that chickens selected for rapid growth actually make less growth hormone. ${ }^{17}$

More recent experiments have also shown a genetic interaction with injected PST in normal pigs. Obese lines of pigs had a greater response than a lean line of pigs. ${ }^{19}$ Modern pigs are slaughtered at a young age. In older heavier pigs, PST will have a greater effect in Pietrains compared to Durocs. ${ }^{20}$ The converse is true at a younger age with slaughter weights below $100 \mathrm{~kg}$.

The use of biotechnology to produce better vaccines was discussed earlier. To take the process a step further genes could be introduced into farm animals to produce disease resistance. ${ }^{18}$ An example would be the gene for tick resistance. It could be transferred from Zebu to European cattle.

The most radical transgenic idea is to replace the mitochondria in cattle skin cells with chloroplasts. Chloroplasts are the photosynthesis cells of plants. This was predicted by Lowell Catlett a futurist at New Mexico State University. ${ }^{21}$ Chloroplasts would enable cattle to eat less food because they could derive a portion of their energy from sunlight. This could be detrimental to the welfare of the animal if it was mismanaged. Cattle are grazing animals. If they were deprived of food and forced to stand in the sun it could be very detrimental to their welfare.

To conclude this section, it is more likely that the creation of transgenic animals has a greater poteintial for creating welfare problems compared to using products derived from technology such as vaccines and hormones.

\section{ANIMAL PHARMACEUTICAL FACTORIES}

Another use for transgenic animals is producing medically valuable substances such as clotting factor for hemophiliacs. These substances would be produced in the milk and could be continually harvested via milking. Researchers at the AFRC Institute of Animal Physiology in England have produced sheep which produce medically useful clotting factor for hemophiliacs and $\alpha$,-antitrypsin. ${ }^{22}$ The ability to produce the anticlotting factor can be passed on to the offspring.

This genetic change appears to have no detrimental effect on the animal's welfare. Michael Fox admits that "If there is no animal suffering following certain genetic changes, then it is difficult to argue against such molecular farming, where animals are used as protein factories." 11 If animals are raised commercially for the 
production of pharmaceutical substances it is essential that they be housed in an environment which provides them adequate stimulation so they do not develop stereotypies and other abnormal behavior. These animals should be kept in a dairy herd environment where they can socialize with herdmates. Housing in individual barren stalls would not be acceptable from a welfare standpoint. Researchers must also be careful not to insert genes or substances which may make the animal sick or cause chronic health problems.

\section{MOSAIC ANIMALS}

Genetic material from two different species are combined to form an animal which is a genetic mosaic. Sheep and goat genes will produce an odd looking animal which has patches of goat tissue and patches of sheep tissue throughout its body. Wool grows out of one body area and goat hair out of another. At the present time their is no practical use for mosaics. However, they did further understanding of how genes work.

I had the opportunity to see and touch a geep (goat-sheep mosaic) at the University of California. The animal was several years old and appeared healthy. It did not appear to be suffering in any way. Ethical concerns will be discussed later in this paper.

\section{ADDING AND DELETING GENES}

Husbandry practices such as castration and dehorning have been critisized as being detrimental to animal welfare. Biotechnology may provide a way to eliminate painful surgery. Some naturally polled (hornless) cattle have undesirable traits compared to the horned varieties. With genetic engineering the horn gene may be able to be selectively removed without affecting the other desirable traits.

Male animals can be immunized against luteinizing hormone. ${ }^{23}$ This results in a castration-like response. Present research using conventional methods produces a somewhat variable response. Perhaps genetic engineering could be used to produce a more effective nonsurgical castration.

The latest developments in biotechnology enable researchers to specifically inactivate specific genes in mice. ${ }^{24}$ This method will enable scientists to probe the purpose of a single gene throughout the life of an animal. This technology will provide great knowledge of biology but it may also be very detrimental to small numbers of mice. However, it is likely to be less invasive and aversive to the mice than many types of research that do not involve biotechnology. This research has tremendous potential to improve the welfare of both people and animals by finding cures for genetic disorders. 


\section{TRANSGENIC ANIMALS AND CLONES IN BIOMEDICAL RESEARCH}

The use of transgenic mice and clones of cells in biomedical research may provide medical breakthroughs. Biotechnology is being used to make discoveries that may provide a cure for autoimmune disorders such as diabetes, rheumatoid arthritis, psoriasis and multiple sclerosis. ${ }^{25,26,27}$ Pigs are being used to learn how to direct new genes into specific tissues instead of allowing them to express themselves all over the body. ${ }^{27}$ This could lead to treatments for clogged arteries and cancer. The new genes would only be active at specific sites. AIDS is another disease where biotechnology is being used to research treatments. Biomedical research utilizing transgenic animals and genetic engineering is absolutely essential to find a cure or a vaccine for many serious human and animal diseases. However, the use of biotechnology to make farm animals more productive is much less important to society than finding cures for serious human and animal diseases. Michael Fox (1989) states "We should ask why we need to genetically engineer farm animals, especially in these times of agricultural surpluses and chronic over production." 13 The number of animals which may have their welfare compromised in biomedical research is a tiny fraction of the numbers of animals used for food. Biomedical and basic research must never be confused with product testing of cosmetics and other substances on animals. Many product testing uses of animals could be replaced with tissue cultures and other substitutes. Some of these nonanimal alternatives are the products of biotechnology research. This is another example of how biotechnology can improve animal welfare.

Previously, the statement was made that farm animals, with increased disease resistance, may be a threat to wildlife habitats. On the other hand, biotechnology and cloning can be used to preserve wildlife. Rare wildlife can be cloned and gestated by common domestic animals.

\section{INDIRECT USES}

Products developed using the tools of biotechnology can also be used as diagnostic tests for diseases or for identification. Branding with hot irons is used as a method of identifying cattle in the United States and other countries. If inexpensive DNA fingerprinting tests could be developed for cattle, stolen animals and their meat could be easily traced. This could eliminate painful branding. Recent research reported at the American Society of Animal Science meetings in 1990 indicate that DNA fingerprinting of livestock may be feasible. ${ }^{28,29}$ DNA fingerprinting could also be used to assist law enforcement officials on determining the origin of products made from poached wildlife.

Biotechnology can also be used to develop faster and more accurate diagnostic tests for animal diseases. Swine dysentary causes severe diarrhea in piglets. Eradication of the disease is difficult because present tests cannot detect carriers which can spread the disease even though they do not show symptoms. A new DNA probe test can now detect carriers and eradication of this disease may now be possible. ${ }^{30}$ 


\section{ETHICAL CONSIDERATIONS}

Some scientists have stated that changing animals with genetic engineering is no different than changing animals with selective breeding. Indiscriminate over selection for single traits in dogs and farm animals has caused many health problems such as hip dysplasia and an extremely nervous temperament in lean fast growing pigs. These pigs are excitable and are very difficult to handle humanely in a high speed slaughter plant. It is a problem pork producers must address before a serious animal welfare problem is created. ${ }^{31}$ Maybe temperament genes could be disassociated from productivity traits. Michael Fox, Humane Society of the U.S. argues that biotechnology cannot be compared to selective breeding because genetic engineering makes it possible to cross species boundries and greatly accelerate genetic change. ${ }^{11}$

The editor of Science also agrees that the use of recombinant DNA greatly accelerates change. ${ }^{32}$ He writes further "we must proceed cautiously in introducing new genes and new combinations of genes into species, long-term experiments are needed to study detrimental effects. We are no where near the knowledge needed to genetically engineer the complex behavior of a wolf or dog. ${ }^{32}$ An original wolf might say to a dog, you have lost your freedom. Your obsequiousness is humiliating to the family Canida." The dog could reply "I am less warlike, far more altruistic and besides its a wonderful standard of living." ${ }^{32}$ Whether society prefers to have wolves or dogs remains to be seen. $^{32}$

There is a point where science and intellectual logic cannot provide all the answers to the ethics of manipulating genes. Ethical decisions are often a matter of personal convictions. Bernard Rollin emphasizes that emotion is a necessary component of morality. ${ }^{33}$ There needs to be a balance between strictly emotional and strictly intellectual avenues of making ethical decisions.

For the last fifteen years I have worked on methods to improve the welfare of farm animals during handling, transport and slaughter. Below I will present my feelings. When I visited a research lab and petted the GEEP (goat-sheep mosaic) I did not feel repulsed. Even though it looked funny it acted like a normal tame animal. It did not appear to be afflicted with any of problems which occur in pigs with human growth genes. It also appeared to be neurologically normal and did not show any signs of excitability or depression. I am repulsed by animals that have been grossly distorted to the point where they have physical problems such as bull dogs and Pietrain pigs. I found a quivering Pietrain boar at a French livestock show pathetic.

There is great concern that livestock housed in intensive farming systems suffer due to boredom and a lack of stimulation. It has been suggested that animals could be genetically changed to adapt them to even more intensive housing. Would it be ethical to create microcephalic farm animals with reduced brain capacity which would not suffer? I find this idea repulsive. One reason I find the idea of microcephalic animals repellent is because I like to interact with animals. I don ' $t$ want to see them turned into machines. That would be moving backward instead of evolving forward. Some scientists may dismiss my remarks as mere emotion, but feelings do have a place in making ethical decisions. People that are involved in an activity day after day can become numb to its ethical implications. On the other hand, people which have had no meaningful contact and are too detached and unknowledgable will also be unable to make sound ethical 
decisions. I have observed workers in slaughter plants abusing animals because they become "numb." ${ }^{34}$ Managers in a distant corporate office in a far away city are too detached to care. Slaughter plants that maintain high standards of human treatment have a person who acts as the "plant conscience." This person is usually an upper manager who has enough involvement to avoid detachment but does not participate to the point where he becomes numb. Biotechnology laboratories also need a person to be the "lab conscience." This person needs to be well informed scientifically but also be somewhat of an outsider so he can question.

Extreme philosophical positions against biotechnology are often made by people who have little technical knowledge or no direct contact with an ill person who could directly benefit from genetic engineering research. It is very likely, that an ardent animal rights activist would soften his stance against biotechnology after he discovered that his own child had hemophilia or diabetes. Two diseases whose victims can benefit from biotechnology research. I have asked several animal rights activists if they would use products derived from animal research on an ill child. Often I got no answer and the question was evaded.

Bernard Rollin discusses moral shifts in his book on Animal Rights and Human Morality. Moral shifting involves feelings. If you visited and interacted with a sick child your moral position may shift towards supporting biotechnology. If you observed an animal tortured by a callous unethical researcher your stance may shift against biotechnology.

Extreme positions which justify absolute freedom of inquiry and that the end always justifies the means are often made by people who have knowledge in one small area and a narrow range of experiences. The become ethically blind. This is why courses in literature, history, ethics and philosophy should be part of a scientist 's and business person 's training. I have observed scientists who softened their stance against animal welfare after they learned more about ethology and animal behavior. They no longer viewed the animals as physiological machines.

Decisions on the ethical use of biotechnology need to be made by a group of well informed individuals. I also believe in the concept of ethical cost. A researcher would have greater justification to perform an invasive or painful procedure to find a cure for AIDS compared to finding a substance to make pigs grow a little faster. A cure for AIDS has a higher ethical priority than the profit motive of a new growth promoter. Causing animals to suffer to make them grow a little faster would not be ethically justified especially in this era of agricultural surpluses.

\section{SYMBIOSIS}

Last year I read an article that had a profound effect on my thinking. The article was titled The Ancient Contract and it presented a natural-historical view of our evolving relationship with animals. ${ }^{35}$ This view presents a middle ground between animal rightists which make the moral status of animals equal to humans and the Cartesion view that treats animals as machines with no feelings. ${ }^{28}$

This is when I really started to think about the biological concept of symbiosis. A symbiotic relationship is mutually beneficial to both organisms. It is not parasitism. 
There are many examples of symbiotic relationships between different organisms in nature. We feed and protect animals from predators. Domestic animals are slaughtered at an early age but they do not suffer the pain of being ripped apart alive by a predator or starving from lack of food. To maintain symbiosis we must treat animals humanely and give them a good life. Housing systems that cause sensory restriction symptoms or abnormal stereotypies would not be acceptable. ${ }^{36}$ Andrew Rowan at Tufts University states, "In many circumstances the animal rights movement over romanticizes nature." 35 On the other hand we must respect animals as sentient beings and that our relationship must be truly symbiotic. To me it is equally repulsive and unethical to use either biotechnology or old-fashioned crossbreeding to create animals that have physical or neurological disabilities. The animal should still be an animal even if it photosynthsizes sunlight. Nervous excitable pigs or microcephalic dairy cows cannot be handled like normal animals. They would have to be put in boxes and treated more like objects. Treating animals with a complex brain as objects is totally wrong. Some of the genetically excitable lines of nervous hybrid pigs cannot be handled humanely in conventional race systems used in slaughter plants. The animals pile up and refuse to walk up the race. Pigs with a calm temperament can be easily handled in these systems.

\section{SANCTITY OF LIFE}

One view is that recombinant DNA techniques violates the sanctity and dignity of life. ${ }^{36}$ I agree with the editor of Science who says we must proceed cautiously but I also think it is important to keep moving forward and advance knowledge. If we stop evolving we will stagnate as a species.

There are some important lessons to learn from history. Medical developments throughout history have been delayed for centuries due to religious taboos about violating the sanctity of the human body. The ancient Greek physician Galen made erroneous conclusions about human anatomy by studying pig anatomy. Over a thousand years elapsed until Andreas Vesalius dared conduct an accurate human dissection in 1543. ${ }^{37}$ Another doctor named Servatus was less cautious in publishing his results and he was burned at the stake for heresy. ${ }^{37}$ After this time the knowledge of medicine proceeded more rapidly. Throughout history there have been other examples of forbidden knowledge. Giordano Bruno who lived at the same time as Vesalius was also burned at the stake because he provided the first concept of an infinite universe. ${ }^{38}$

I design equipment for slaughtering animals and I often have many thoughts about the relationship between humans and other forms of life. I got in this business because I wanted to reduce suffering. Equipment that reduces suffering that I developed is now being installed in major beef slaughter plants. Hunting and agriculture were the first science and technology. I have no desire to give up science and technology on the other hand we must become much more sensitive to ethical and environmental concerns. Science, engineering and the use of our intellect is an important part of being human, but morality is also essential. I have experienced moral shifts due to experience. Ten years ago I sometimes questioned whether people should use animals for food. Today I feel that humans can use animals for food and research in an ethical manner. First of all we must practice symbiosis with the animals and make our relationship with them 
mutually beneficial to both. We must never view animals as machines that we can just use. Treating animals as things would violate the sanctity of life. Over the years I have used my engineering skills to improve slaughtering systems. When the new systems are supervised by ethical managers the cattle experience no pain and almost no fear or excitement. Recently I had the opportunity to drive the cattle into the newest state of the art system. I felt good about it because there was no fear or suffering. As a result of this experience my position on the quality of animal housing systems is hardening. Some of the housing systems for pigs provide a poor quality of life. People that abuse animals should be punished.

Sometimes I have thought, "Maybe someday biotechnology will make the slaughter plant obsolete." If this happens, there will be much greater ethical questions than killing animals for food. Humans will be the first species who could control their own evolution. With biotechnology, plants could be changed to grow protein with all the essential amino acids. Maybe meat could be grown on the vine as "beef steak tomatoes." I do not find this idea repulsive because a block of muscle would have no brain or nervous system.

The process of sequencing genes is slow, but new developments such as the scanning probe microscope may greatly accelerate sequencing of both the human and animal genomes. Maybe the genetic sequence of many kinds of animals could be stored in a super computer and food shortages could be eliminated by inserting the genes for photosynthesis into people. We would no longer have to grow plants or animals for food.

Maybe aggressive warlike behaviors could be controlled by making genetic changes in our brains. Maybe biotechnology can help save us from third world dictators blowing up the world with the atomic bomb. If an atomic war breaks out all people, animals and the environment will suffer greatly. Sequencing the humane genome may unlock many secrets such as: why do people have such a large cerebral cortex and the chimpanzee has a smaller brain even though both species have $98 \%$ of the same genes? Why do pigs have a genome similar to humans except that the chromosome pieces are in a different order $?^{40}$ There are possibilities of expanding both human and animal intelligence. It may be only a matter of changing a few regulator genes to delay maturity of the brain and allow it to further develop (Jaak Panksepp, Bowling Green State University, 1989). Probing into these great mysteries will create serious ethical questions. What knowledge should be forbidden or allowed?

The huge mega science projects of the 1990 's such as sequencing the human genome ${ }^{33}$ the Hubble Space Telescope and the super collider replace the pyramid and cathedral building of our ancesters. There is a basic human drive to figure out who and what we are. One of the main purposes of the Hubble Space telescope is to see all the way to the beginning of the universe. Years ago, scientists were burned at the stake for talking and writing about these ideas. There are no simple answers to ethical questions. History tells us, that yesterday's heresy is accepted science of today.

I take a middle road approach of advancing biotechnology carefully. Humans as a species will stagnate if we don ' $t$ keep progressing. We certainly do not want to plunge into a terrible time like the dark middle ages of Europe. Using our intellect and advancing our knowledge is an important human trait. 
"It is true that free inquiry is integral to our humanity, but so too is morality. So the quest for knowledge must be tempered with moral concern." ${ }^{33}$ A total lack of moral concern can lead to atrocities such as the Nazi medical experiments. We must avoid intellectual stagnation which retarded the hisory of medical knowledge but on the other hand be moral. Vesalius was a pioneer in cutting through superstition but he was also callous. In some of his anatomy experiments he tied down living animals and cut them open. Vesalius 's greatest contributions were his anatomy studies which were conducted on dead humans. Vesalius went to an extreme when he started torturing live animals. Again there needs to be a balance between compassion and the quest for knowledge.

I will summarize once again, we should proceed cautiously but we should definitely proceed. Biotechnology can be used for noble, frivolous or evil purposes. Decisions on the ethical use of this powerful new knowledge should not be made by extremists or people purely motivated by profit.

\section{REFERENCES}

1 T. Grandin, Welfare requirements of handling facilities. In: S.H. Baxter and J.A.D. MacCormack (eds.), Farm Animal Housing and Welfare, Martinus Nijhoff, Dortdrecht, The Netherlands, pp. , 1983.

2 T. Grandin, Double rail restrainer conveyor for livestock handling, J. Agric. Engineering Res., 41 (1988) 327-338.

3 L.J. Machlin, Effect of porcine growth hormone on growth and carcass composition in the pig, J. Anim. Sci., 35 (1972) 794-800.

4 American Society for Animal Science, Growth and development abstracts. J. Anim. Sci. 68 (1990) (Suppl. 1), 272-323.

5 E. Kanis et al., Effect of recombinant porcine somatotropin on growth and carcass quality in growing pigs, J. Anim. Sci., 68 (1990) 1193-1200.

6 E.J. Day, Future research needs to focus on a new, old problem. Feedstuffs, July 23, 1990, p. 12.

7 B.R. Schicker, PST: Production Potential. Large Anim. Vet., 45(3) (1990) 13-14.

8 D.M. Rudman et al., Effects of human growth hormone in men over 60 years old, New England J. Med., 323 (1990) 1-6.

9 Anon. Scientists present new information on BST use, Feedstuffs, August 6, 1990, p. 11.

10 N. Effertz, Shape up, Monfort launches a program to crowd $95 \%$ of the problems into 5\% of the cattle. Beef Today, February, 1990, pp. 22-24.

11 B. Straw et al., Injection reactions in swine, Anim. Health Nutr., December, 1986, pp. 10-19.

12 M. Fox, Animal welfare concerns of genetic engineering and biotechnology, World Soc. Prot. Anim., Biennial Meeting, 1990.

13 M. Fox, Genetic engineering and animal welfare. Appl. Anim. Behav. Sci., 22 (1989) 105-113.

$14 \quad$ R.D. Palmiter et al., Nature (London) 300 (1982) 611.

15 R.D. Palmiter et al., Metallothionein -- Human GH fusion genes stimulate growth in mice, Science 222 (1983) 809-814. 
16 R.E. Hammer et al., Production of transgenic rabbits, sheep and pigs by microinjection, Nature (London) 315 (1985) 680-683.

17 J. Cherfar, Molecular biology lies down with the lamb, Science 249 (1990) 124126.

18 V.G. Pursell et al., Genetic engineering of livestock, Science 244 (1989) 12811287.

19 J.T. Yen et al., Effects of porcine somatotropin (PST) administration on growth performance and carcass measures of genetically lean and obese swine. J. Anim. Sci. 68(Suppl. 1), (1990) 292 (Abstract).

20 E. Kanis et al., Effect of recombinant porcine somatotropin on growth and carcass quality in growing pigs: Interactions with genotype, gender and slaughter weight, J. Anim. Sci. 68 (1990) 1193-1200.

21 S.R. Cooper, What if she were green? National Cattlemen, August 1990, p. 20.

22 A.J. Clark, Expression of human anti-hemophilic factor IX in the milk of transgenic sheep, Biotechnology 7 (1989) 487-492.

23 B.D. Schanbacher, Effects of active immunization of the ram and bull against luteinizing hormone, Theriogenology 24 (19 ) 59-71.

24 D. Baltimore, Science Watch, Biology Breakthrough. Technology Review, August/September 1990, p. 70.

25 E.G. Nabel, G. Plautz and G.J. Nabel, Site specific gene expression in vivo by direct gene transfer into the arterial wall, Science, 249 (1990) 1285-1288.

26 A. Sinha et al., Autoimmune diseases: The failure of self tolerance, Science, 248 (1990) 1380-1388.

27 L.C. Burkly et al., Tolerance in transgenic mice expressing major histocompatibility molecular extrathymically on pancreatic cells, Science, 248 (1990) 1364-1368.

28 M.J. Martin, B.A. Didion and C.L. Markert, Restriction fragment length polymorphism (RFLP) analysis in swine using a commercial DNA fingerprinting kit, J. Anim. Sci., Suppl. 1 (1990) 243 (Abstract).

29 D.A. Wall and S.K. Davis, Evaluation of DNA fingerprinting in cattle, J. Anim. Sci. Suppl. 1 (1990) 243 (Abstract).

30 C. Swinehart, New DNA probe opens door to swine dysentary eradication. National Provisioner, August 27, 1990, p. 14.

31 T. Grandin, Environment and genetic effect on hog handling. Amer. Soc. Agric. Eng. Tech. Paper No. 894514 (1989) St. Joseph, Michigan.

32 D. Koshland, The engineering of species, Science 244 (1989) 1233.

33 B.E. Rollin, Animal Rights and Human Morality, Prometheus Books, Buffalo, New York, 1981.

34 T. Grandin, Behavior of slaughter plant and auction employees towards animals, Anthrozoos 1 (1988) 205-213.

35 S. Budiasky, The ancient contract, U.S. News and World Report, March 20, 1989, pp. 75-79.

36 T. Grandin, Effect of reafring environment and environmental enrichment on behavior and neural development of young pigs, Dissertation, University of Illinois, Urbana, 1989. 
37 M. Fox, Genetic engineering biotechnology: Animal welfare and environmental concerns, Appl. Anim. Behav. Sci., 20 (1988) 83-94.

38 H.W. Haggard, Devils, drugs and doctors. The story of the science of healing from medicine man to doctor, Harper Bros. Books, New York, 1929.

39 C. Singer and A.E. Underwood, A short history of medicine. Oxford University Press, Oxford, England, 1962.

40 J. Trefil, Seeing atoms, Discover, June, 1990, pp. 55-60.

41 S. Young, Genetic markers put pigs on the map, New Scientists, July 28, 1990, p. 46.

42 R. Lewin, In the beginning was the genome, New Scientist, July 21, 1990, pp. 3438. 